National Marine

Fisheries Service

NOAA
Fishery Bulletin

a established in 1881 a
Spencer F. Baird

First U.S. Commissione of Fisheries and founder of Fishery Bulletin
Abstract-Atlantic halibut (Hippoglossus hippoglossus) is an increasingly valued commercial fish and its recent population growth has attracted the attention of fisheries scientists and managers both within and outside Canada. With renewed transnational interests in this species, fishery managers have relied on existing, but limited, ecological information for multilateral discussions on shared allocations of catch. To address this dearth of information, we modeled species distribution using maximum entropy, where by survey catch data were related to environmental data to quantify habitat suitability. We then calculated the amount of suitable habitat for juvenile Atlantic halibut per Northwest Atlantic Fisheries Organization (NAFO) divisions, within and outside Canada's Exclusive Economic Zone. Among NAFO divisions, we found a strong relationship between the availability of suitable habitat for juvenile Atlantic halibut, and both current and historical fisheries landings. Results are consistent with the nursery-size hypothesis which states that the amount of available juvenile habitat is related to the level of adult production. The majority of occupied suitable habitat is found on the southwestern half of Canada's Scotian Shelf, whereas the U.S. and international waters off Newfoundland have ample suitable habitat to support larger populations. Quantifying habitat suitability and linking this suitability to stock abundance and distribution is an important step toward an ecosystem approach for the management of Atlantic halibut.

Manuscript submitted 11 May 2017. Manuscript accepted 24 November 2017. Fish. Bull. 116:107-121 (2018).

Online publication date: 26 January 2018. doi: 10.7755/FB.116.2.1

The views and opinions expressed or implied in this article are those of the author (or authors) and do not necessarily reflect the position of the National Marine Fisheries Service, NOAA.

\title{
Strong relationship between commercial catch of adult Atlantic halibut (Hippoglossus hippoglossus) and availability of suitable habitat for juveniles in the Northwest Atlantic Ocean
}

\author{
Kiyomi J. French \\ Nancy L. Shackell (contact author) \\ Cornelia E. den Heyer \\ Email address for contact author: Nancy.Shackell@dfo-mpo.gc.ca \\ Bedford Institute of Oceanography \\ Department of Fisheries and Oceans Canada \\ P.O. Box 81006 \\ Dartmouth, Nova Scotia B2Y 4A2, Canada
}

In the Northwest Atlantic Ocean, Atlantic halibut (Hippoglossus hippoglossus) range from Greenland to Virginia, United States (Bigelow and Schroeder, 1953; Collette and KleinMacPhee, 2002). In Canada, it is currently managed as 2 stocks. The larger stock, which is the subject of this article, extends from the Southern Grand Banks of Newfoundland, across the Scotian Shelf, and into the Gulf of Maine (Fig. 1). The stock ranges over multiple North Atlantic Fisheries Organization (NAFO) divisions and, importantly, spills over international boundaries into the territorial waters of the United States, Overseas France, and the international High Seas regulatory area. Despite a history of overfishing (Grasso, 2008), Canadian assessments show that the stock has rebounded in the last decade, is benefiting from a period of high recruitment ( $\mathrm{DFO}^{1,2}$;Trzcinski

${ }^{1}$ DFO (Department of Fisheries and Oceans Canada). 2015. 2014 assessment of Atlantic halibut on the Scotian Shelf and southern Grad Banks (NAFO Divisions 3NOPs4VWX5Zc). Can. Sci. Advis. Secr. Sci. Advis. Rep. 2015/012, 16 p. [Available from website.]

2 DFO (Department of Fisheries and Oceans Canada). 2015. Stock Assess- and Bowen, 2016), and was the third most valuable groundfish in Canada in 2015 (Economic Analysis and Statistics, Department of Fisheries and Oceans Canada, landings data, available from website). The Canadian fishery is now certified "sustainable" by the Marine Stewardship Council (Marine Stewardship Council, Track a Fishery, website). In contrast, under the U.S. Endangered Species Act, Atlantic halibut is listed as a "Species of Concern" from Labrador, Canada, to southern New England (USA) $\left(\mathrm{NOAA}^{3}\right)$, and the 2015 results of the U.S. halibut assessment model were rejected owing to limited information (an action that has enforced the view that the stock is still in an overfished state) $\left(\right.$ Hennen $\left.^{4}\right)$.

ment of Atlantic Halibut of the Gulf of St. Lawrence (NAFO Divisions 4RST) for 2013 and 2014. Can. Sci. Advis. Secr. Sci. Advis. Rep. 2015/023, 15 p. [Available from website.]

${ }^{3}$ NOAA. 2013. Species of concern: Atlantic halibut, 2 p. [Available from website.]

${ }^{4}$ Hennen, D. 2015. Atlantic halibut. In Operational assessment of 20 Northeast groundfish stocks, updated through 2014. U.S. Dep. Commer., Northeast. Fish. Sci. Cent. Ref. Doc. 15-14, p. 171179. [Available at website.] 


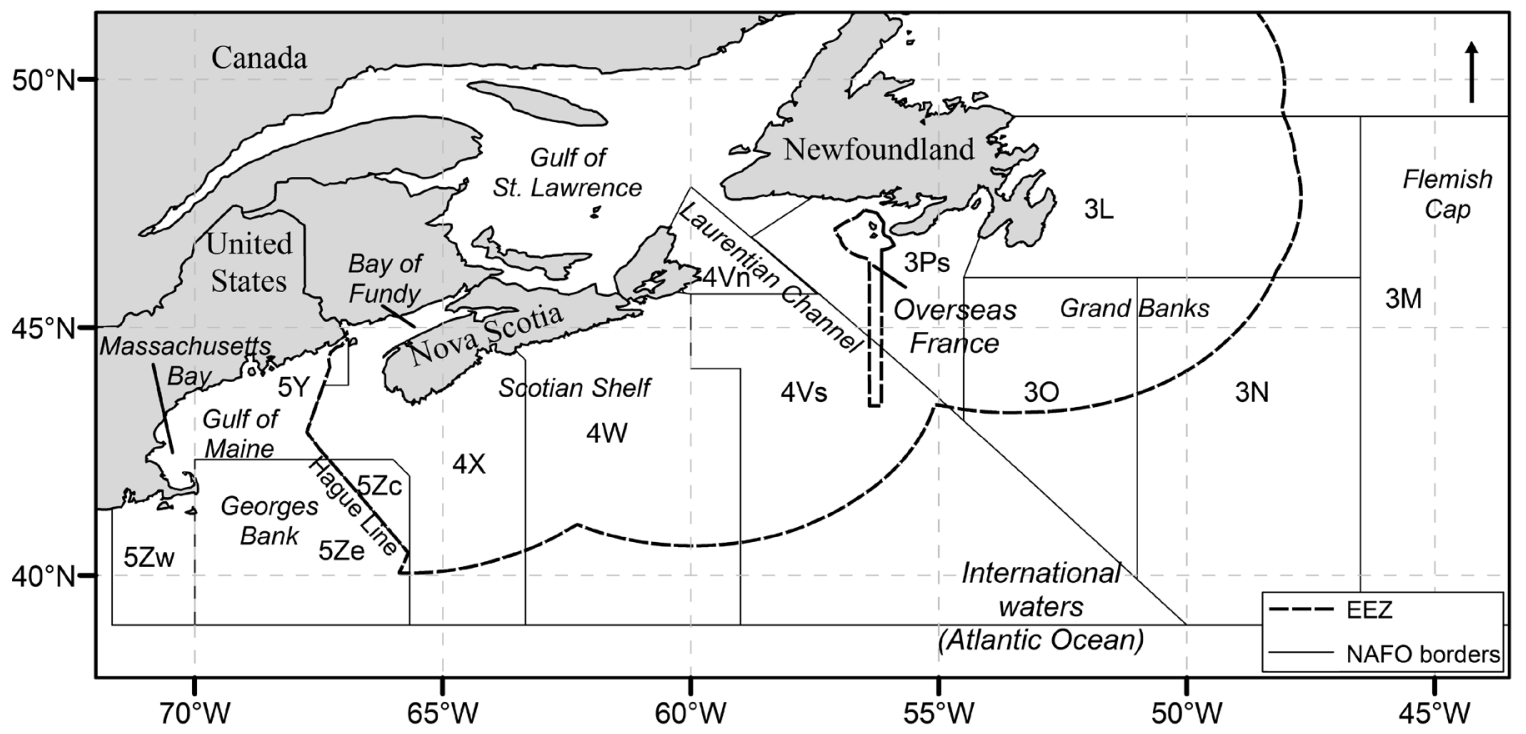

Figure 1

Map of the range of the stock of Atlantic halibut (Hippoglossus hippoglossus) on the Scotian Shelf and southern Grand Banks, and areas of interest for this study in which the relationship between commercial catch of adult Atlantic halibut and availability of suitable habitat for juveniles in the northwest Atlantic Ocean was examined (by using data from surveys conducted during 2001-2013 and maximum entropy modeling). Thin, solid lines indicate the borders of North Atlantic Fisheries Organization (NAFO) divisions, within and outside of Canada's Exclusive Economic Zone (EEZ).

Informal reports from both the U.S. and French fishing industries suggest that halibut are becoming more abundant within their jurisdictions and fishery managers have expressed renewed commercial interest in the Atlantic halibut fishery. However, there is limited ecological information to support transnational discussions concerning shared allocations of catch (Bigelow and Schroeder, 1953; McCracken, 1958; Stobo et al., 1988; Neilson et al., 1993; Cargnelli et al., 1999). A major challenge facing Atlantic halibut research is a lack of data on the past and present distributions and abundances of this species. Historically this species became of commercial interest only after decades as discarded bycatch in the cod (Gadus morhua) fishery and was quickly exploited to a critical state in the 1850 s (Grasso, 2008). Before the establishment of a fisheryindependent index of abundance (1970s), Atlantic halibut were heavily impacted by fishing activity for other groundfish, and the current period of high recruitment especially in Canada, is a relative measure compared with abundances during the regional groundfish moratorium of the early 1990s (Collette and Klein-MacPhee, 2002; Grasso, 2008).

Atlantic halibut is the largest of all flatfish (Bigelow and Schroeder, 1953; Collette and Klein-MacPhee, 2002). It is long lived and sexually dimorphic; males reach maturity at smaller sizes $(77-80 \mathrm{~cm}$ in total length [TL]) than females (103-125 cm TL) (Bowering, 1986; Trumble et al., 1994; Sigourney et al., 2006). This species is capable of long-distanced migrations, but the majority of tagged fish are recaptured locally (McCracken, 1958; Jensen and Wise, 1961; Neilson et al.5; Stobo et al., 1988; Kanwit, 2007; den Heyer et al., 2012; Seitz et al., 2016) and therefore may reflect populations with both resident and migratory individuals (e.g. Nielsen and Seitz, 2017) or seasonal migrations to putative spawning areas (e.g., Le Bris et al., 2017). This finding indicates lower levels of mixing than those under the long-held presumption that the stock is a large, interbreeding population (Seitz et al., 2016). The tendency to remain stationary until the age of 4-6 years and a homing response to spawning grounds have been observed among Atlantic halibut in Norway (Godø and Haug, 1988). In the Northwest Atlantic, a lack of known spawning-site location and egg or larvae data has meant that distributions of this species during the earliest life history stages are unknown. Moreover, because current standardized trawl surveys are limited by depth, they lead to uncertainties in determining halibut presence and activities in deeper waters. Studies with electronic tags to elucidate northwest migration patterns and spawning locations of Atlantic halibut (e.g. Armsworthy et al., 2014; Seitz et al., 2016; Murphy et al., 2017; Le Bris et al., 2017) will ultimately improve our ability to define and manage halibut stocks. However, owing to growing commercial interests, there is an immediate need for scientific information to support management decisions.

\footnotetext{
${ }^{5}$ Neilson, J. D., W. R. Bowering, and A. Fréchet. 1987. Management Concerns for Atlantic halibut (Hippohlossus hippoglossus) in the Canadian North Atlantlc. CAFSAC Res. Doc. 87/73, 23 p. [Available from website.]
} 
Availability of suitable habitat is the cornerstone of several ecological theories. In particular, the theory of density-dependent habitat selection describes how animals occupy the most suitable habitat first and expand to more marginal habitat when competition for resources in the prime habitat reduces the fitness benefit of that area (Fretwell and Lucas, 1970; MacCall, 1990). In practice, this concept has been documented in multiple marine systems (Swain and Wade, 1993; Marshall and Frank, 1995; Rangeley and Kramer, 1998; Shackell et al., 2005). There is also extensive evidence that range size and abundance of a species are correlated, and that availability of suitable habitat is strongly and positively correlated with total abundance (Gaston and Blackburn, 1996; Brosse et al., 1999; Holbrook et al., 2000; VanDerWal et al., 2009).

Any life history stage is subject to habitat limitation and to the nursery-size hypothesis that stems from the idea that recruitment and adult fish population density can be constrained by the availability of nursery habitat because of density-dependent mortality during juvenile life stages (Iles and Sinclair, 1982; Rijnsdorp et al., 1992; Gibson, 1994; Beverton, 1995). The idea has resurged in the results of recent studies that have shown a solid relationship between availability of nursery habitat and the recruitment of adults (Sundblad et al., 2014; Wilson et al., 2016). It is theorized that because younger fish are likely to have a narrower range of suitable habitat, regardless of how well-defined their nursery grounds are, juvenile habitat falls within a restricted domain of the adult range (Gibson, 1994; Beverton, 1995). To explore this notion, Sundblad et al. (2014) mapped nursery habitat distributions for predatory fish between mainland Finland and Sweden's archipelago region of the Baltic Sea, and found that they can be quantified and used to help estimate potential adult production. Similarly Wilson et al. (2016) added support to the nursery size hypothesis; they found a relationship between increased recruitment and the presence of juvenile flatfish and concluded that accurate predictions of flatfish nursery locations can be useful for population management.

We use these principles to support evidence-based management by quantifying suitable habitat for juvenile Atlantic halibut and relating it to adult landings in directed fisheries. In this article, we expand upon the work of Shackell et al. (2016) who hypothesized that there was ample suitable habitat available in U.S. waters to support a larger juvenile population. We estimate the distribution of suitable juvenile habitat in each NAFO division, within and outside Canada's Exclusive Economic Zone (EEZ). We then express the amount of suitable habitat $(\mathrm{SH})$ per NAFO division as a relative value ( $\mathrm{SH}-$ based shares: the proportion of the total available suitable habitat that falls within each NAFO division), and show that these values are related to the proportional shares of commercial fishery landings (adult) among NAFO divisions allocated on the basis of total landings of Atlantic halibut (abundance-based shares [landings]). We propose that this relationship can be considered a baseline for expected juvenile and fishery production per NAFO division. We further propose that suitable habitat can be used as a proxy for production in the absence of more detailed ecological information. In areas where the relationship between expected juvenile habitat and fishery p roductivity substantially stray from a 1:1 relationship, further research is required to understand the mechanisms controlling the population, and to support the spatial management of this fishery.

\section{Material and methods}

\section{Modeling species distribution with a correlative approach}

Species distribution models are designed to predict the limits of geographic range and habitat suitability for a selected species, by using functions that relate physiological (mechanistic) or distributional (correlative) data to areas of unknown occupancy (Kearney and Porter, 2009; VanDerWal et al., 2009). Maximum entropy is a correlative approach that can be used for modeling species distribution because it describes the relationship between survey (coordinate) and environmental data (raster layers) (Elith et al., 2011). It is commonly used to study the distributions of invasive species, shifts in distribution related to climate change, and the spatial diversity of species (Phillips and Dudik, 2008; Elith et al., 2011; Fitzpatrick et al., 2013).

As it pertains to the model, entropy is a measure of the uncertainty in a data set (Cover and Thomas, 1991); a uniform distribution would represent complete uncertainty. A maximum entropy model uses multimodal logistic regression with information from observational data and maximizing entropy based on environmental constraints (Jaynes, 1957; Elith et al., 2011). The logistic output from this model is a prediction layer that maps the relative habitat suitability of all locations on the basis of prevailing conditions where the species has been observed. From habitat suitability, we can infer the probability of species presence (VanDerWal et al., 2009). The output scales from 0 to 1 , where 0.5 represents the relative habitat suitability and probability of presence, where environmental conditions are 'typical for presence' (Phillips et al., 2006; Phillips and Dudik, 2008; Elith et al., 2011; details in Suppl. Material). VanDerWal et al. (2009) found that for many species, a positive relationship exists between habitat suitability and local abundance, and that these models provide useful insights into spatial patterns of abundance.

We chose to model with maximum entropy to take advantage of its ability to accurately predict in unsampled locations, the several parameterizations available to account for biases in the data, and the continuous and common scale of model outputs that enable direct comparison among models (Phillips et al., 2006). Additionally, unlike Shackell et al.'s (2016) use of a generalized additive model for a similar analysis, our method 
enabled us to predict across a much larger area, and because the research vessel survey data are zero inflated (absences are less certain than presences among survey data), we were able to take advantage of the presence-only modeling capabilities of maximum entropy (Sundblad et al., 2014).

\section{Data}

We modeled habitat suitability by using research survey data from 2001 through 2013-a timeframe that captures the current period of high Atlantic halibut recruitment. The U.S. National Marine Fisheries Service, NOAA, and Fisheries and Oceans Canada (DFO) have conducted seasonal or annual research surveys (or both) to foster an improved understanding of groundfish abundance and distribution since the early 1960s (NOAA) and 1970s (DFO), (Azarovitz, 1981; Simon and Comeau, 1994). The Canadian surveys sample NAFO divisions off Newfoundland and Labrador (NF), Nova Scotia (NS), and within the Northern and Southern Gulf of St. Lawrence (GSL) (Fig. 1). The U.S. surveys sample Georges Banks, the Gulf of Maine, and the Bay of Fundy (here, we collectively refer to these regions as "U.S." (Fig. 1). All surveys were conducted with bottom-trawl gear and fish abundance, biomass, water depth, and bottom temperature were recorded in a comprehensive database, which can be publically accessed from the Ocean Biogeographic Information System (available from website; Shackell et al., 2005; $\left.\mathrm{DFO}^{6}\right)$. Since the start of these surveys $(\sim 1963)$, they have been performed during all seasons and 7 different gear types have been used. A wide variety of fish species are captured over the course of each cruise; Atlantic halibut are usually caught as juveniles (annual median fish length $40-50 \mathrm{~cm}$ TL), and larger halibut are thought to outswim the trawls (Trzcinski and Bowen, 2016). Samples were collected from all the NAFO divisions of interest, although there are variations in survey seasonality, intensity, and gear type, and there is difficulty in sampling over rough terrain. Because of these limitations and variations between surveys there are unsampled regions throughout the study area (Suppl. Tables 1 and 2), all of which can produce an uneven and biased data set because some regions have more representative (larger in quantity and more evenly distributed) sample sets than others.

If bias is not accounted for, the predictive power of the model is lessened (Philips and Dudik, 2008). Fourcade et al. (2013) explored 5 parameterizations available to maximum entropy modeling that are commonly used to correct for bias, thus enabling models to predict more accurately in under-sampled locations. These methods include 1) systematic sampling (data are placed on a grid and one random sample per cell

\footnotetext{
${ }^{6}$ DFO (Department of Fisheries and Oceans Canada). 2016 2015 Maritimes research vessel survey trends on the Scotian Shelf and Bay of Fundy. Can. Sci. Advis. Secr. Sci. Resp. 2016/011, 66 p. [Available from website.]
}

is used in analysis), 2) clustering samples (data are subset by using a principal component analysis that identifies spatial autocorrelation), 3) restricting the background (selecting only background points that fall within the extent of the survey [comparable to using locations where surveys yield true absence of fish]), 4) incorporating a bias file (values are weighted by using a raster that reflects the sampling effort or sampling probability), and 5) geographically splitting the data (the model is computed separately for each area and results are combined) (Fourcade et al., 2013). While designing our model, we tested several of these data correction techniques and compared their ability to improve output diagnostics; however we did not attempt to systematically sample or cluster data because this approach would have caused too many data to have been lost.

We incorporated 5 environmental raster layers in our model: 1) bathymetry (created with the GEBCO 30 arc-second grid obtained from the General Bathymetric Chart of the Oceans (available from website), 2) slope (created by calculating percent rise from the GEBCO 30 arc-second grid), 3 and 4) seasonal mean bottom temperatures for summer and winter in degrees Celsius, and 5) the range in mean temperature between summer and winter, at a $0.1^{\circ}$ resolution. Temperature data were obtained from the Global Ocean Reanalyses and Simulations (GLORYS; Mercator Ocean, available from website], which describe monthly mean ocean climate conditions at a $1 / 4^{\circ}$ lat. $\times$ long. resolution. We chose to work with GLORYS temperature data instead of the data that were collected from the trawl censors because GLORYS provided a complete and uniform coverage of the area that is more conducive to interpolation. We limited our model to 5 predictor variables because the use of excessive variables can lead to overfitting the data (Philips and Dudik, 2008). We selected variables that describe groundfish habitat (the bottom), and variables for which there were data for the entire study area. We interpolated the temperature layers by using ordinary kriging and 2001 through 2011 data. To prepare data for interpolation, we grouped monthly measures by season (summer: July-September, winter: January-March), calculated the mean annual temperatures for each season, and then assigned the 10-year average to each datum point. Finally, we incorporated regional variability in temperature by calculating the annual mean range in temperature by taking the difference of the seasonal means, and averaging these values across the entire sampling period.

We used 3 shapefiles (NAFO, available from website) to spatially classify the study area for spatial comparisons: NAFO boundaries, the EEZ, and the Hague line (Fig. 1). The waters stretching from the northern limits of Baffin Island to Cape Hatteras are known as the NAFO Convention Area, which is divided into subareas, divisions, and subdivisions (Halliday and Pinhorn, 1990). Although some of the areas of interest are formally referred to as "subdivisions," we refer to all areas as "NAFO divisions" throughout this analysis. We 


\begin{tabular}{|c|c|c|}
\hline \multicolumn{3}{|c|}{$\begin{array}{l}\text { The } 4 \text { models of species distribution used to test different combinations of parameterization techniques } \\
\text { used, in turn, to correct data biases in this study of the relationship between commercial catch of adult } \\
\text { Atlantic halibut (Hippoglossus hippoglossus) and availability of suitable habitat for juveniles in the } \\
\text { northwest Atlantic Ocean. Correction parameters are those outlined by Fourcade et al. (2013). Cross- } \\
\text { validation produced values for the area under the omission curve (AUC), which indicate a model's } \\
\text { proficiency in differentiating between presence and absence sites. }\end{array}$} \\
\hline Correction parameters & Method & AUC \\
\hline Default & & 0.83 \\
\hline Restricted background & $\begin{array}{l}\text { Select only background points that fall within } \\
\text { the extent of the survey: use true absence locations }\end{array}$ & 0.81 \\
\hline $\begin{array}{l}\text { Restricted background } \\
+ \text { bias file }\end{array}$ & $\begin{array}{l}\text { Select only background points that fall within the } \\
\text { extent of the survey: use true absence locations }+ \\
\text { weight values by incorporating the raster layer that } \\
\text { reflects the sampling effort or sampling probability }\end{array}$ & 0.80 \\
\hline $\begin{array}{l}\text { Restricted background } \\
+ \text { split }\end{array}$ & $\begin{array}{l}\text { Select only background points that fall within the } \\
\text { extent of the survey: use true absence locations }+ \\
\text { geographically splitting the data, compute the model } \\
\text { separately for each area, then combine results }\end{array}$ & 0.89 (mean) \\
\hline
\end{tabular}

subset the NAFO shapefile to include only the divisions that represent the extent of the Southern Grand Banks and Scotian Shelf stock. The NAFO Convention Area was further subdivided by 1) the Canadian EEZ, which is drawn $370 \mathrm{~km}$ (200 nautical mi) from shore to mark the extent of national jurisdiction over waters and the beginning of shared international resources, and 2) the Hague line, which delineates the border between waters of Canada and the United States (Halliday and Pinhorn, 1990; Anderson, 1998) (Fig. 1).

To measure adult abundance of Atlantic halibut, we used 3 data sets from the Atlantic halibut fishery. For recent values, we used commercial landings by division from 2010 through 2014 (DFO, seafisheries landings, available from website); these data reflect both data from directed fisheries and data on bycatch. We also used Butler and Coffen-Smout's (2017) map of landings, by catch weight, to spatially represent the MARFIS data. This map shows a 5-year (2010-2014) composite of landings in kilograms per $2 \times 2$ minute lat.xlong. grid (Butler and Coffen-Smout, 2017). As a measure of historical adult abundance, we used historical fishery landings data gathered by McCracken (1958). He gathered information on landings from several governing agencies and was able to find sufficient location data to identify important areas (fishing grounds) in the Northwest Atlantic, and he expressed the landings as the annual percentage of shares of halibut landings per NAFO division. These historical landings (1953-1954) predate the intensive Atlantic cod (Gadus morhua) trawl fishery of the 1970s and 1980s (Myers et al., 1996) and are considered to represent a regulation-free fishery, when fishing crews were free to relocate operations as they pleased, and maximize their catch per unit of effort (Gillis et al., 1993). Because the distribution of fishing vessels typically achieved an ideal free distribution (Gillis et al., 1993), the footprint of the unregulated fisheries is a good representation of historical spatial distribution of adult halibut. Supporting this notion, the abundancebased shares estimated by McCracken using unregulated fisheries data, along with his report of important and stable fishing grounds, were used to allocate fishing shares proportionally among NAFO divisions when the Canadian halibut fishery was first regulated in 1988 (Neilson et al.5).

\section{Analysis}

All statistical analyses were performed in RStudio, vers. 3.3.2 (RStudio, Inc., Boston, MA), and maps were produced in ArcMap, vers. 10.4.1(ESRI, Redlands, CA). We used functions available in the package dismo, vers. 1.1-4, in $\mathrm{R}$, vers. 3.3.2 ( $\mathrm{R}$ Core Team, 2016) to build 4 models of species distribution with maximum entropy. Each model tested a different combination of parameterization techniques that can help correct various types of sampling bias as outlined by Fourcade et al. 2013 (Table 1). Our models combined data from 18 research surveys (Suppl. Table 1). Input consisted of the 1980 records of halibut presence, a random subset of 5000 records of absence, and raster layers for

\footnotetext{
${ }^{7}$ Mention of trade names or commercial companies is for identification purposes only and does not imply endorsement by the National Marine Fisheries Service, NOAA.
} 
5 environmental variables (covariates). To account for depth-related biases (because the surveys rarely exceed $400 \mathrm{~m}$, although we know that adult halibut can inhabit depths of 1000-m (Miller et al., 1991; Cargnelli et al., 1999), the extent of the output prediction layer was limited to the area of the strata sampled. Because of this restriction, it is highly likely that some potentially suitable areas were not mapped; however we contend that we are capturing the majority of juvenile habitat because there is an association between depth and halibut size (Bigelow and Schroeder, 1953; Collette and Klein-MacPhee, 2002) because juveniles typically occupy shallower depths and move deeper with age (e.g., Sigourney et al., 2006).

Our model with the strongest diagnostics incorporated a restricted background (with true absence points) and its data were divided by survey (Table 1). By default, a model will select a set of random "background" locations (in unsampled locations) to represent pseudo-absence points. By using true absence points in place of the background data, valuable information is incorporated into the model. We ran 3 separate models for separate surveys: NS and U.S., GSL, and NF, and then combined the 3 output layers, keeping the largest habitat suitability value for each location. This modeling approach made full use of the data available, and running separate models accounted for inherent differences among the surveys (sampling effort, catchability of gear type, and seasonality (Suppl. Tables 1 and 2)) and enabled a consideration of smaller scale trends and potential spatial variation in habitat preferences in different regions.

To evaluate the models, we performed a cross-validation and compared "area under omission curve" (AUC) values. For cross-validation, we withheld $20 \%$ of the input data (test data) when running the model, and then compared corresponding predicted values from the resulting habitat-suitability layer with the true values at the test-data locations (a good model can accurately predict the likelihood of species presence in test-data locations). Cross-validation also produces AUC values that indicate the proficiency of a model in differentiating between presence and absence sites and is the standard for maximum entropy assessment (Elith et al., 2006; Phillips and Dudik, 2008). On a scale from 0 to 1 , an AUC value greater than 0.9 is widely accepted as "excellent" or "high" accuracy, and less than 0.6 is generally considered a "fail" because 0.5 means probabilities are no better than random (Phillips and Dudik, 2008; Halvorsen, 2013). For the remainder of the analysis, we used the habitat-suitability layer from the strongest performing model, and we also excluded the GSL because tagging evidence supports the management of this area as that of a separate stock (McCracken, 1958; Neilson et al.5; Stobo et al., 1988; den Heyer et al., 2012; Le Bris et al., 2017).

For regional comparisons, we partitioned the habitat-suitability layer using the NAFO and EEZ shapefiles as boundaries and calculated statistics within each division. We quantified suitable habitat by using a classification rule: a pixel was classified as "suitable" if its predicted habitat-suitability value was greater than 0.54. Typically values greater than 0.5 are accepted as the probability of presence of halibut at sites where environmental conditions are 'typical' of presence (Phillips and Dudik, 2008; Elith et al., 2011), and by increasing this threshold, we increased this likelihood. The proportion of the total available suitable habitat to fall within each NAFO division $\left(\hat{p}_{i}\right)$ and the catch shares per NAFO division allocated on the basis of abundance of Atlantic halibut $\left(\hat{p}_{i}\right)$ were both calculated as

$$
\hat{p}_{\mathrm{i}}=\frac{s_{\mathrm{i}}}{\sum_{\mathrm{i}=1}^{\mathrm{j}} s_{\mathrm{i}}},
$$

where the summed suitable habitat $\left(\mathrm{km}^{2}\right)$ or the summed survey locations with species presence within $i$ NAFO division $\left(s_{\mathrm{i}}\right)$, were divided by the totals summed across all $j$ NAFO divisions. We will refer to these values as "SH-based shares" and "abundancebased shares," respectively.

Assuming a constant relationship between potential abundance and availability of suitable habitat, we plotted the relationship between SH-based shares and abundance-based shares (survey data) against a 1:1 baseline. We interpreted this baseline as "expected habitat productivity" where proximity to the baseline indicates whether the productivity of an area is above, meeting, or below expectations. The abundances determined from research surveys were derived from the same data set used to quantify juvenile habitat. Any positive relationship between habitat and abundance determined from research surveys would suggest that the amount of habitat is related to juvenile production. To explore the empirical relationships between suitable habitat availability and fishery productivity (e.g., Brosse et al., 1999; Holbrook et al., 2000; VanDerWal et al., 2009) we plotted the relationship between SHbased shares and commercial landings in recent and historical fisheries (abundance-based shares [landings]). This approach allowed us to test the feasibility of using the 1:1 baseline and to model suitable habitat shares as a proxy for production and to explore the potential for similarities between adult and juvenile halibut distributions. We further explored this potential overlap in choice habitat by overlaying the habitat-suitability layer with the 2010-2014 Canadian commercial fisheries map of landings, by catch weight (Butler and Coffen-Smout, 2017), and by extracting habitat suitability values associated with recent landings data which have a minimum legal fish size of 81 cm TL $\left(\mathrm{DFO}^{2}\right)$.

There are several assumptions inherent in this approach. First, is that good juvenile habitat leads to high adult abundance. Although we do not have direct evidence to support this assumption, it is supported by the nursery-size hypothesis [stated earlier], and inferred by density-dependent mortality during early lifehistory stages (Iles and Sinclair, 1982; Rijnsdorp et al., 1992; Gibson, 1994; Beverton, 1995; Sundblad et al., 


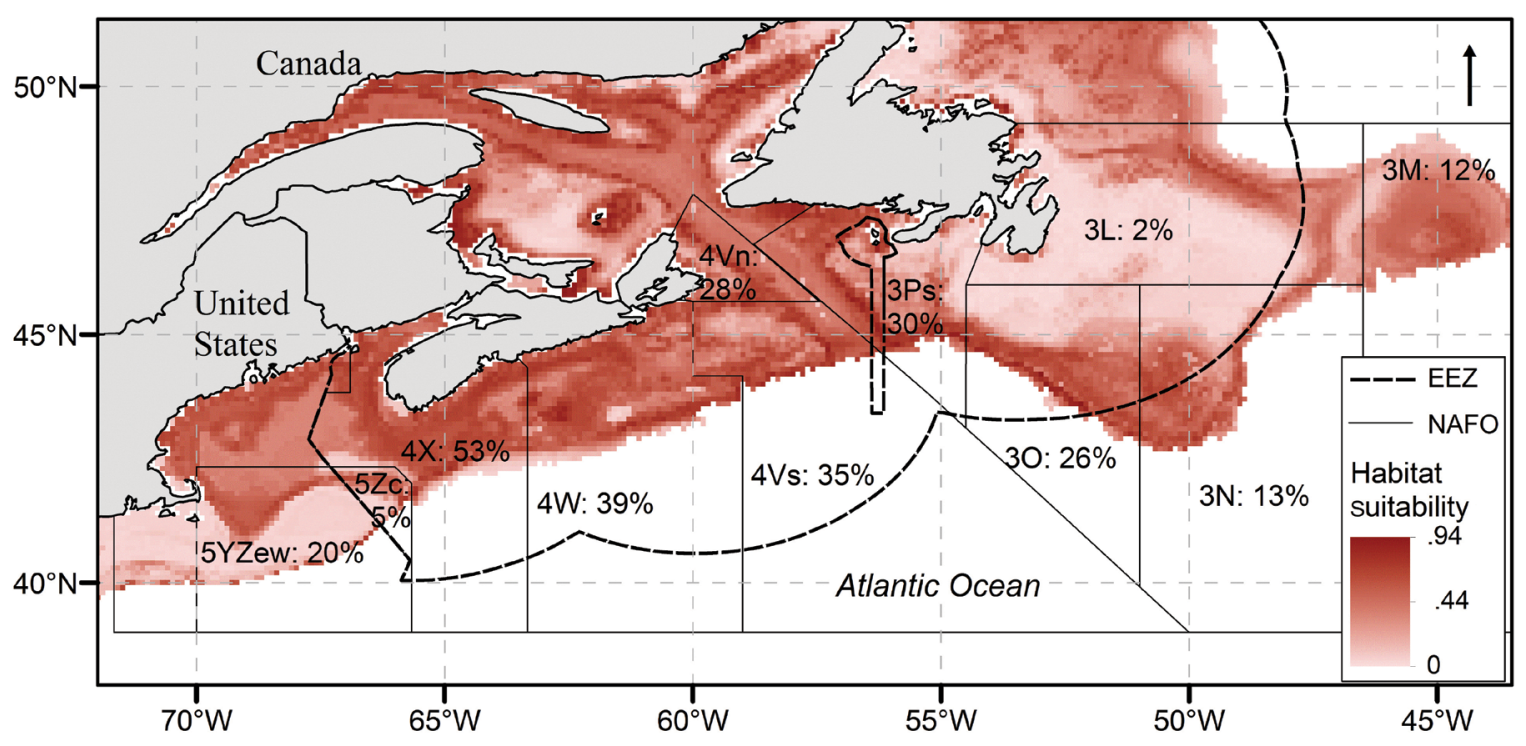

Figure 2

Map of areas in the northwest Atlantic Ocean characterized as suitable habitat for juvenile Atlantic halibut (Hippoglossus hippoglossus) and estimated by using maximum entropy species distribution modeling and data from trawl surveys conducted from 2001 to 2013. This habitat suitability layer is a composite output from 3 maximum entropy models for 3 regions in the northwest Atlantic Ocean for which the largest cell value was retained. Habitat suitability is represented on a scale of $0-1$, with 0.5 representing the relative habitat suitability and probability of presence of Atlantic halibut where environmental conditions are typical for presence. Percentages represent the total percentage of the area surveyed within each North Atlantic Fisheries Organization (NAFO) division that had suitable habitat. Values for the NAFO divisions in U.S. waters (5Y, 5Zw, and 5Ze) were grouped together.

2014; Wilson et al., 2016). There is also the assumption that there are low levels of emigration from these areas. This assumption is consistent with tagging studies, which have reported that the majority of recaptures occur in the area of initial tagging (McCracken, 1958; Jensen and Wise, 1961; Neilson et al. ${ }^{5}$; Stobo et al., 1988; Kanwit, 2007; den Heyer et al., 2012; Seitz et al., 2016). Finally, the use of landings data as a proxy for abundance has been extensively debated; here we use the spatial distribution of landings as a surrogate for the spatial distribution of the stock (e.g., Pauly et al., 2013).

\section{Results}

Model output was a spatial representation of relative habitat suitability for predominantly juvenile Atlantic halibut. Overall, $22.5 \%$ of the total surveyed area was characterized as suitable habitat for juvenile halibut (Fig. 2) (we will refer to this as "suitable habitat"). Cross-validation on 20 iterations of the model produced average AUC values of 0.90 for NS and U.S., 0.85 for NF, and 0.92 in the GLS (on a scale from 0 to 1, with 1 being the best possible score) (Suppl. Fig. 1, A-C). When we compared the habitat suitability values with the test data, locations with presence of Atlantic halibut were far more frequently associated with areas with high habitat-suitability values and absence with low values; this result also promoted confidence in the model (Suppl. Fig. 1, G-I).

The greatest proportional amount of suitable habitat fell within the divisions $4 \mathrm{X}$ and $4 \mathrm{~W}$, which are adjacent NAFO divisions that cover a large section of the Scotian Shelf (Table 2; Fig. 2). Divisions 3Ps (off the southern coast of Newfoundland) and $5 \mathrm{Y}, 5 \mathrm{Ze}$, and $5 \mathrm{Zw}$ (Maine) also contained proportionally large amounts of suitable habitat (Table 2; Fig. 2). The majority of the suitable habitat in the United States was concentrated near shore and along Georges Banks, whereas in 3Ps, it was found along the edge of the Laurentian Channel and toward the deeper slopes (Fig. 2). The remaining NAFO divisions had smaller, although noteworthy, amounts of suitable habitat shares (Table 2).

The southern Grand Banks (Newfoundland) fall within NAFO divisions $3 \mathrm{~L}, 3 \mathrm{~N}$, and $3 \mathrm{O}$ and possess rich fishing grounds, but unlike the Scotian Shelf (where suitable habitat was predicted to be widely available), suitable habitat in this region was located mostly toward the slope (Fig. 2). A noteworthy amount of suitable habitat $\left(18,162 \mathrm{~km}^{2}\right)$ was outside Canada's EEZ on the southern Grand Banks and the Flemish Cap (Table 3). International waters are sampled less frequently than areas within the EEZ and therefore there is more uncertainty around abundances in these regions.

Variable contributions describe how well a change in a covariate value contributes to changes in habitat 


\section{Table 2}

The proportional share of suitable habitat for Atlantic halibut (Hippoglossus hippoglossus) within each North Atlantic Fisheries Organization (NAFO) division, and as a percentage of total surveyed area within each NAFO division, calculated by using data from trawl surveys conducted from 2001 to 2013 in 3 regions of the northwest Atlantic Ocean: Newfoundland and Labrador (3L, 3M, 3N, 3O, and $3 \mathrm{Ps})$, Nova Scotia and the United States $(4 \mathrm{Vn}, 4 \mathrm{Vs}, 4 \mathrm{~W}, 4 \mathrm{X}, 5 \mathrm{Y}, 5 \mathrm{Zc}, 5 \mathrm{Ze}$, and 5Zw), and the northern and southern Gulf of St. Lawrence. Habitat suitability for Atlantic halibut was modeled on a scale of $0-1$ by using maximum entropy. Proportion of suitable habitat within region (\%) represents the availability of suitable habitat at the division level, and SH-based shares represent suitable habitat availability in relation to the entire study area. In and out refer to inside and outside Canada's Exclusive Economic Zone, and sampling intensity, by division, is given in the number of sampling sets per square kilometer. For locations of NAFO divisions, see the map in Figure 1.

\begin{tabular}{|c|c|c|c|}
\hline NAFO division & $\begin{array}{l}\text { Sampling intensity } \\
\left(\text { sets } / \mathrm{km}^{2}\right)\end{array}$ & $\begin{array}{c}\text { SH-based shares } \\
(\%)\end{array}$ & $\begin{array}{l}\text { Proportion of suitable } \\
\text { habitat within region } \\
(\%)\end{array}$ \\
\hline 3L (in) & 0.023 & 2.2 & 1.6 \\
\hline $3 \mathrm{~L}$ (out) & 0.026 & 0.0 & 0.0 \\
\hline 3M (cap) & 0.002 & 12.3 & 4.1 \\
\hline $3 \mathrm{~N}$ (in) & 0.022 & 6.7 & 1.2 \\
\hline $3 \mathrm{~N}$ (out) & 0.033 & 20.0 & 3.9 \\
\hline 30 (in) & 0.027 & 24.0 & 8.3 \\
\hline 30 (out) & 0.054 & 44.3 & 1.3 \\
\hline $3 \mathrm{Ps}$ & 0.030 & 29.6 & 12.1 \\
\hline $4 \mathrm{Vn}$ & 0.012 & 28.2 & 3.9 \\
\hline $4 \mathrm{Vs}$ & 0.024 & 35.4 & 8.1 \\
\hline $4 \mathrm{~W}$ & 0.020 & 38.8 & 16.5 \\
\hline $4 \mathrm{X}$ & 0.020 & 53.4 & 23.1 \\
\hline $5 \mathrm{Zc}$ & 0.103 & 4.7 & 0.3 \\
\hline $5 \mathrm{Y}, 5 \mathrm{Ze}, 5 \mathrm{Zw}$ & 0.031 & $19.7 \%$ & $15.6 \%$ \\
\hline
\end{tabular}

\section{Table 3}

Habitat suitability for Atlantic halibut (Hippoglossus hippoglossus) modeled on a scale of 0-1 by using maximum entropy and data from trawl surveys conducted during 2001-2013 in the northwest Atlantic Ocean. To identify suitable habitat in international waters, for North Atlantic Fisheries Organization (NAFO) divisions that comprise both international and Canadian waters, habitat suitability was modeled both as a percentage within (\%In) and outside (\%Out) Canada's Exclusive Economic Zone (EEZ). Suitable-habitat availability within and outside of the EEZ was estimated as a percentage of the total surveyed area. NA represents areas that (on the basis of model output) contained no suitable habitat.

\begin{tabular}{|c|c|c|c|c|c|}
\hline NAFO division & Area & $\begin{array}{l}\text { Area surveyed } \\
\qquad\left(\mathrm{km}^{2}\right)\end{array}$ & $\%$ In & $\%$ Out & $\begin{array}{c}\text { No. of } \\
\text { samples }\end{array}$ \\
\hline $3 \mathrm{~L}$ & Northern Grand Banks & 171,489 & $1.6 \%$ & $0 \%$ & 3879 \\
\hline $3 \mathrm{M}$ & Flemish Cap & 64,612 & NA & $4.1 \%$ & 108 \\
\hline $3 \mathrm{~N}$ & Southern Grand Banks & 74,153 & $1.2 \%$ & $3.9 \%$ & 1922 \\
\hline 30 & Southern Grand Banks & 43,400 & $8.3 \%$ & $1.3 \%$ & 2052 \\
\hline
\end{tabular}

suitability, and in turn, how closely each variable is related to productivity. All of our modeled variables contributed to the prediction in all 3 subset regions (Suppl. Fig. 1, D-F). Percent rise and seasonal range in bottom temperature consistently made relatively small contributions, whereas the contribution of seasonal bottom temperatures and depth varied by region (Suppl. Fig. 1, D-F). NS and U.S., and the GSL had more limited depth profiles, and the majority $(80 \%)$ of the fish occurred in less than $190 \mathrm{~m}$ and $290 \mathrm{~m}$, respectively (Table 4). In contrast, a much broader depth profile was portrayed in $\mathrm{NF}$, where the majority of the catch was below $560 \mathrm{~m}$ (Table 4 , Suppl. Fig. 2). Owing to a much wider distribution 


\section{Table 4}

Depth, slope, and bottom temperature (summer, winter, and range) were used as predictor variables to model the distribution and availability of suitable habitat for Atlantic halibut (Hippoglossus hippoglossus) by using data from trawl surveys conducted from 2001 to 2013 in the northwest Atlantic Ocean. Empirical cumulative distributions (ECDs), which describe the odds that a positive survey set occurred (Atlantic halibut were present) across the available range of environmental conditions, for each predictor variable, were calculated for 3 regions in the northwest Atlantic Ocean: Nova Scotia and U.S. waters (NS and U.S.), Newfoundland and Labrador (NF), and the northern and southern Gulf of St. Lawrence (GSL). Values in the 10\% and $90 \%$ columns provide the range for the majority (middle 80\%) of the positive sets in each region, and the $D$ statistics from Kolmogorov-Smirnov (K-S) tests are all close to 0, supporting the notion that there is no statistically significant difference between environmental conditions at the locations of positive sample data sets and the entire data set and that both data sets are drawn from the same range of variables. B. temp=bottom temperature.

\begin{tabular}{|c|c|c|c|c|c|}
\hline \multirow[b]{2}{*}{ Region } & \multirow[b]{2}{*}{ Variable } & \multicolumn{2}{|c|}{ ECD } & \multicolumn{2}{|c|}{$\mathrm{K}-\mathrm{S}$ test } \\
\hline & & $10 \%$ & $90 \%$ & $D$ statistic & $P$-value \\
\hline NS and U.S. & Depth (m) & -193.4 & -65.0 & 0.0026 & 1 \\
\hline $\mathrm{NF}$ & Depth $(\mathrm{m})$ & -556.1 & -88.7 & 0.0010 & 1 \\
\hline GSL & Depth (m) & -281.0 & -30.2 & 0.0022 & 1 \\
\hline NS and U.S. & Slope (\% rise) & 0.0 & 1.5 & 0.0000 & 1 \\
\hline $\mathrm{NF}$ & Slope (\% rise) & 0.1 & 4.6 & 0.0000 & 1 \\
\hline GSL & Slope (\% rise) & 0.1 & 1.5 & 0.0000 & 1 \\
\hline NS and U.S. & Summer b. temp. $\left({ }^{\circ} \mathrm{C}\right)$ & 4.2 & 8.7 & 0.0002 & 1 \\
\hline $\mathrm{NF}$ & Summer b. temp. $\left({ }^{\circ} \mathrm{C}\right)$ & 2.9 & 6.7 & 0.0001 & 1 \\
\hline GSL & Summer b. temp. $\left({ }^{\circ} \mathrm{C}\right)$ & 1.5 & 5.8 & 0.0004 & 1 \\
\hline NS and U.S. & Winter b. temp. $\left({ }^{\circ} \mathrm{C}\right)$ & 3.7 & 7.7 & 0.0002 & 1 \\
\hline NF & Winter b. temp. $\left({ }^{\circ} \mathrm{C}\right)$ & 2.6 & 5.4 & 0.0001 & 1 \\
\hline GSL & Winter b. temp. $\left({ }^{\circ} \mathrm{C}\right)$ & -0.2 & 3.7 & 0.0004 & 1 \\
\hline NS and U.S. & B. temp. range $\left({ }^{\circ} \mathrm{C}\right)$ & -0.7 & 2.1 & 0.0002 & 1 \\
\hline $\mathrm{NF}$ & B. temp. range $\left({ }^{\circ} \mathrm{C}\right)$ & -0.4 & 1.4 & 0.0001 & 1 \\
\hline GSL & B. temp. range $\left({ }^{\circ} \mathrm{C}\right)$ & -0.1 & 5.3 & 0.0004 & 1 \\
\hline
\end{tabular}

of sample depths in NF, this analysis could benefit from a higher sampling effort in deeper waters across the range; however, with the highest suitability falling well within the depth range of the survey strata, we do not believe that the depth limitation hindered the prediction of suitable habitat for juveniles. Summer bottom temperature had the highest contribution to the NS and U.S., and NF models, whereas winter bottom temperature contributed the most to the GSL model (Suppl. Fig. 1, D-F). The majority of fish caught in NS and U.S. were caught between summer temperatures of $4.2^{\circ} \mathrm{C}$ and $8.7^{\circ} \mathrm{C}$; a slightly increased prevalence occurred toward the warmer temperatures (Table 4, Suppl. Fig. 2). In NF there was a similar range with a shift toward colder summer temperatures; the middle $80 \%$ of juveniles were found in waters from $2.9^{\circ} \mathrm{C}$ to $6.7^{\circ} \mathrm{C}$ (Table 4 ). Alternatively, in GSL, there was a lean toward cooler summer temperatures, between $1.5^{\circ} \mathrm{C}$ and $5.8^{\circ} \mathrm{C}$ (Table 4 , Suppl. Fig. 2). These temperature windows are similar to those from GSL pop-up satellite archival tagging studies from Le Bris et al. (2017) and Murphy et al. (2017). Among regions, the environmental variable windows of occurrence of juveniles overlap with slight variations in temperature and depth at the extremes. Lower and upper values correspond with regional differences in habitat characteristics that are evident when the empirical cumulative distributions of reginal samples are compared (Suppl. Fig. 2).

$\mathrm{SH}$-based shares were directly related to abundancebased shares (survey data), supporting the idea that the 1:1 line can be considered a baseline for expected productivity from each region (Fig. 3A). In turn, both suitable habitat shares and abundance-based shares (survey data) were related to abundance-based shares (landings) in historical (1953-54) and recent commercial fisheries (2010-14) (Fig. 3, B-D). The recent abundance-based shares (landings: 2010-14) from the halibut fishery were also very similar to abundance-based shares (survey data) from 2010 through 2013 (Fig. 3C), and when plotted against suitable habitat availability, relations fell very close to the $1: 1$ line of expected productivity (Fig. 3B).

There was a strong spatial overlap between halibut fishery landings and suitable habitat (Fig. 4; Butler and Coffen-Smout, 2017). The highest proportion of the 2010 through 2014 catch occurred in division $4 \mathrm{X}$, which contained the largest $\mathrm{SH}$-based share (Fig. 4A). The 

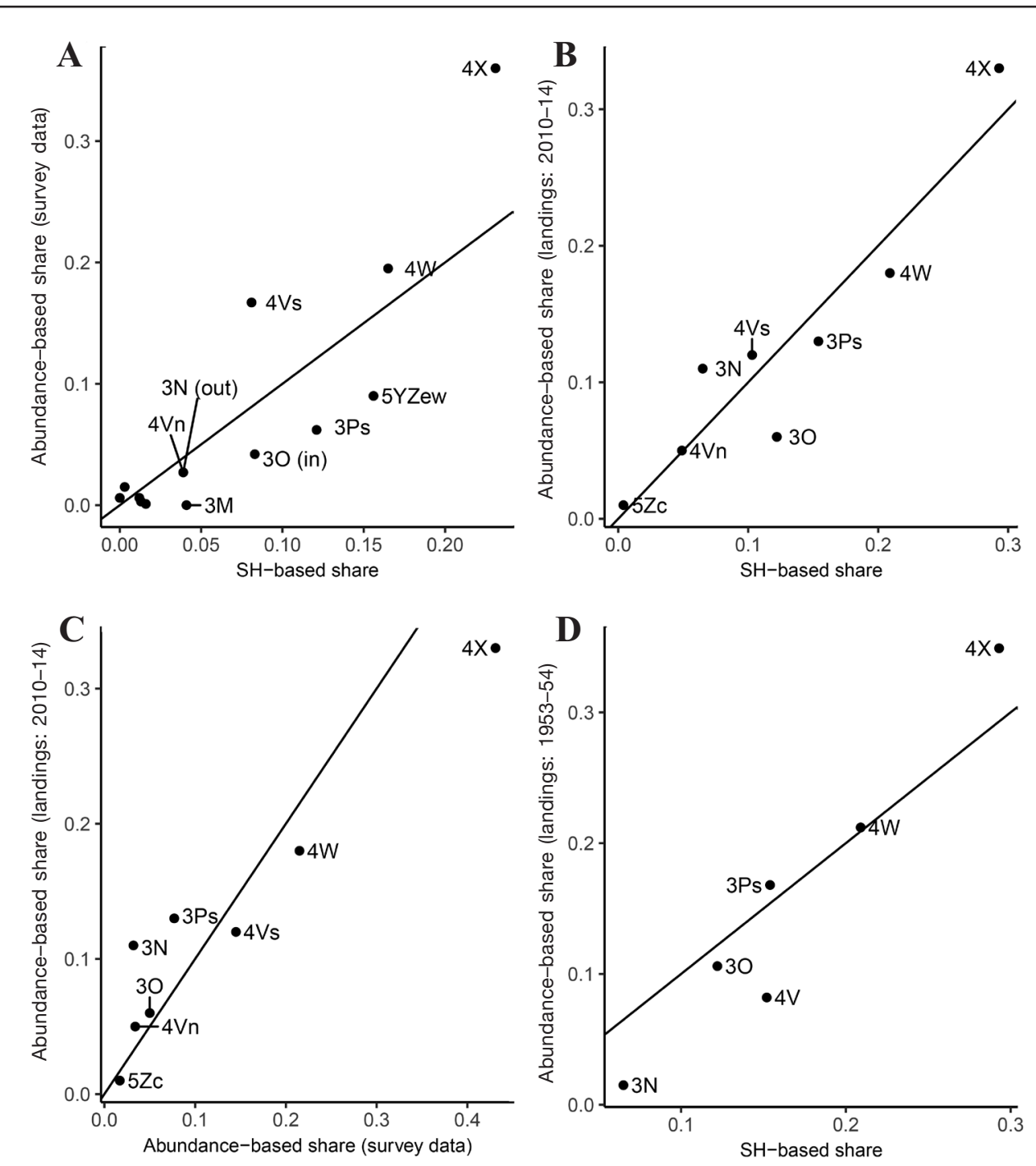

Figure 3

Linear relationships between the availability of suitable habitat and proportional abundances of Atlantic halibut (Hippoglossus hippoglossus), by North Atlantic Fisheries Organization (NAFO) division, in relation to the 1:1 line which indicates a baseline for expected productivity for each NAFO division. (A) The suitable habitat (SH)-based share (the proportion of the total suitable habitat available within each NAFO division), versus abundance-based share (survey data) (the proportion of the total positive survey sets within each NAFO division), based on data from trawl surveys conducted from 2001 to 2013. Unlabeled points (near the x:y axis) are 3L (out) and $5 Z$ c, clustered above the 1:1 line, and 3L (in), 3N (in), and 3O (out), below the 1:1 line. (B) SH-based share versus abundance-based share (landings) (the proportion of the total landings to occur within each NAFO division), based on commercial fishery data for 2010-2014. (C) Abundancebased share (survey data) versus abundance-based share (landings), based on commercial fishery data for 2010-2014. (D) SH-based share versus abundance-based share (landings), based on commercial fishery data for 1953-1954 (McCracken, 1958).

spatial overlap between landings and high suitability values (Fig. 4A) is also supported by the relation between habitat suitability and commercial landings (see histogram [Fig. 4B]), which shows catch frequencies increasing with habitat suitability. To further explore this relationship, we performed a linear regression that predicted landings as a function of suitable habitat availability. The coefficient of multiple determination $\left(R^{2}\right)$ was 0.68 , habitat suitability was significant for landings with a level of marginal significance $(P)$ of 0.0117 , and for a few large residuals included in divisions $3 \mathrm{O}$ (below) and $4 \mathrm{X}$ (above). 
A

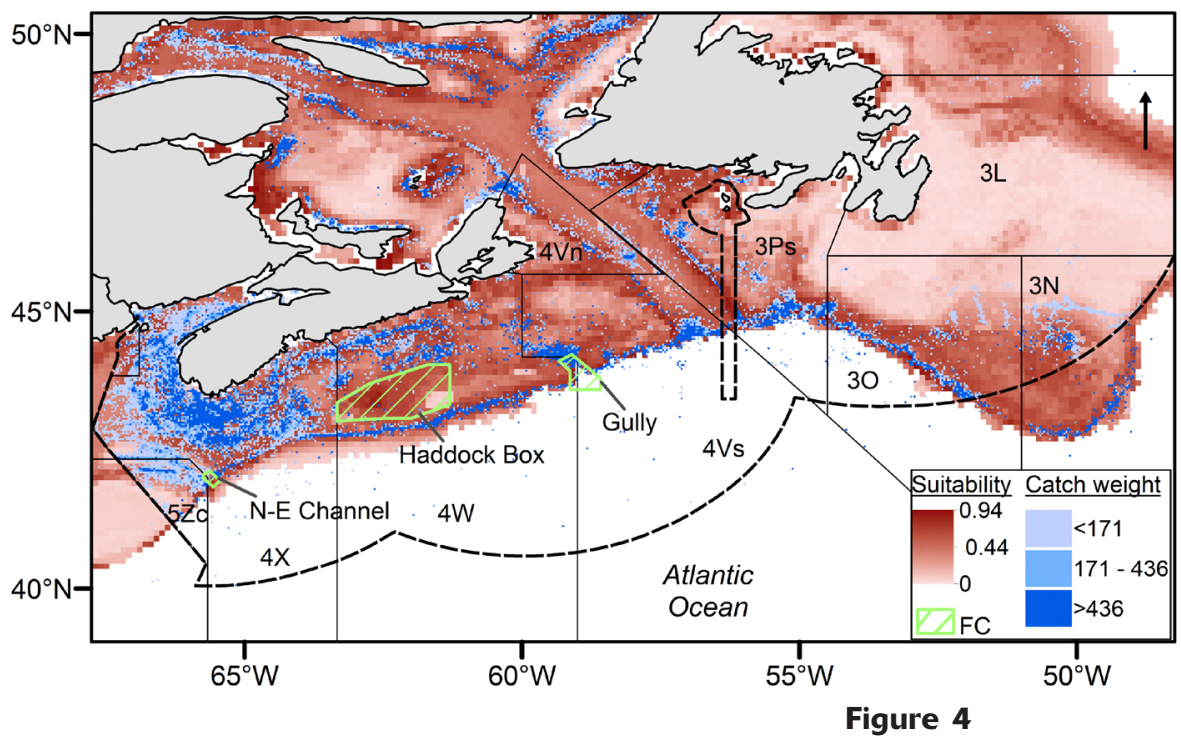

B

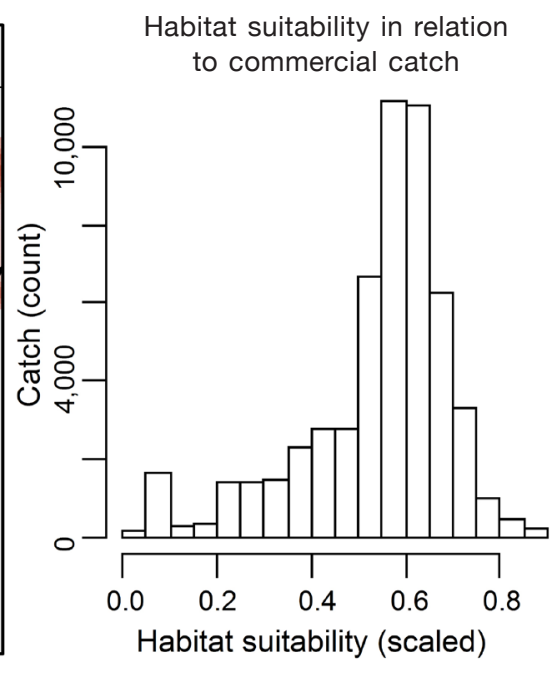

Relationship between commercial landings of adult Atlantic halibut (Hippoglossus hippoglossus) during 2010-2014 and suitability of habitat for juvenile Atlantic halibut in the northwest Atlantic Ocean. (A) The habitat-suitability layer, developed with data from trawl surveys conducted during 2001-2013, overlaid with the map of catch weight from directed fisheries and bycatch landings from Butler and Coffen-Smout (2017). Fishery closures (FCs) include substantial conservation areas, marine protected areas, and nursery areas where fishing of Atlantic halibut is restricted or not permitted. (B) Histogram of habitat suitability versus commercial catch, showing the correspondence between landings and scaled habitat suitability values.

\section{Discussion}

We provide evidence to support the nursery-size hypothesis, which states that the amount of juvenile habitat available is related to adult production (Iles and Sinclair, 1982; Rijnsdorp et al., 1992; Gibson, 1994; Beverton, 1995; Sundblad et al., 2014; Wilson et al., 2016). We found a direct relationship between juvenile and fishery production within NAFO divisions, and a proportional relationship between suitable-habitat availability, and stock productivity. This is consistent with Wilson et al. (2016), who reported that recruitment among 5 flatfish species is limited by nursery area. They further found that juvenile abundance was related to suitable- habitat availability and, in turn, to the recruitment and abundance of adults. This result is also in agreement with tagging studies which consistently find that most tagged halibut are caught within $200-\mathrm{km}$ or less of the location of release (McCracken, 1958; Jensen and Wise, 1961; Neilson et al. ${ }^{5}$; Stobo et al., 1988; Kanwit, 2007; den Heyer et al., 2012; Seitz et al., 2016), and with more recent research that shows a high connectivity within patches of $227 \mathrm{~km}^{2}$ (Boudreau et al., 2017)

In this study, NAFO divisions that fall on the 1:1 baseline of the relationship between the SH-based shares and abundance-based shares (survey data) can be considered to be meeting productivity expectations, whereas areas that fall above or below the baseline are exceeding or below expectations, respectively (see Fig.
3). When compared with suitable-habitat availability, juvenile abundance in NAFO divisions $4 \mathrm{Vs}, 4 \mathrm{~W}$, and $4 \mathrm{X}$ exceeded expectations, and fell short in NAFO divisions $5 \mathrm{Y}, 5 \mathrm{Ze}, 5 \mathrm{Zw}, 3 \mathrm{O}$, and $3 \mathrm{Ps}$ (Fig. 3A). This finding was consistent with previous research that revealed areas with persistently high juvenile halibut abundance within the most productive NAFO divisions (Boudreau et al., 2017). Several factors may be contributing to such trends: variations in current and historic fishing pressures, migrations, prey availability, and environment. Over the past few decades, fishery closures and no-take protected areas, for example, have been established throughout the northwest Atlantic (Butler and Coffen-Smout, 2017). In NAFO divisions $4 \mathrm{Vs}, 4 \mathrm{~W}$, and 4X, the Haddock Box (nursery area), The Gully Marine Protected Area, and the Northeast Channel Coral Conservation Area are substantial areas where trawling and other fishing methods are highly limited or not permitted (Butler and Coffen-Smout, 2017). These areas also have high habitat-suitability values and are located in NAFO divisions where SH-based shares, juvenile abundance, and commercial landings are all high (Fig. 4). Closed areas may also explain why yearround closures on Georges Bank were followed by a dramatic increase in yellowtail flounder populations (Fogarty and Murawski, 2004). Closed areas on the Scotian Shelf could be benefiting Atlantic halibut and contributing to the stock rebound, both by providing habitat protection and by reducing halibut bycatch in other fisheries. 
NAFO divisions $5 \mathrm{Y}, 5 \mathrm{Ze}$, and $5 \mathrm{Zw}$ fell short in juvenile abundance despite adequate suitable habitat availability. Consistent with our findings, Shackell et al. (2016) detected low abundance in relation to suitable-habitat availability in U.S. waters. They, and others, have proposed that this low abundance could be the product of finer-scale stock structure or a history of overfishing (or both) (Seitz et al., 2016; Shackell et al., 2016). Certainly historic fishing pressure is a plausible explanation for the observed low abundances in divisions 5Y, 5Ze, and 5Zw (Grasso, 2008). As biomass decreased during the 1800 s in nearshore fishing grounds, exploitation progressed farther offshore and also began to include juvenile populations (Grasso, 2008). The expansion of the fishery extended out from Massachusetts Bay (Fig. 1), which was the first region to see populations decline and which endured the longest period of intense exploitation (Grasso, 2008). This area, once the home of the commercial fishery for Atlantic halibut, has yet to see a rebuilding of halibut stocks (Hennen ${ }^{4}$ ). The general consensus is that halibut were repeatedly depleted in the United States and more recently depleted throughout their range in the 1990s (Grasso, 2008; Trzcinski and Bowen, 2016). The varying rates of putative recovery throughout the range may be a reflection of smaller-scale stock structure within this stock unit. Boudreau et al. (2017) observed the temporal persistence of several core areas of high juvenile halibut abundance alongside the disappearance of others. A noteworthy core area that disappeared in the 1980s was the area along the shelf edge in NAFO divisions $3 \mathrm{O}$ and $3 \mathrm{Ps}$ (divisions that we identified as underperforming), while persistent core areas in NAFO divisions $4 \mathrm{Vs}, 4 \mathrm{~W}$, and $4 \mathrm{X}$ are associated with our highest performing divisions. Boudreau et al.'s (2017) research supports the Shackell et al. (2016) hypothesis that subpopulations may exist within this Atlantic halibut stock. The erosion of subpopulations could explain why some divisions in our analysis fell below the 1:1 line of expected habitat productivity.

Knutsen et al. (2007) observed genetic subpopulation structure among Greenland halibut (Reinhardtius hippoglossoides) and that differentiation increased with distance. They theorized that 2 genetically different populations exist and that ocean currents play a major role in determining population structure (during larval stages). Notably, for this species, dissimilarity between management units and stock structure was identified by genetic analysis (Knutsen et al., 2007). If subpopulations exist, assessing distinct stocks as a single large stock often runs the risk of overestimating stock size; such a practice was likely responsible for the collapse of the stock of Atlantic cod (Gadus morhua) (e.g., Sterner, 2007). True spatial overlap between management units and actual underlying population structures supports accurate stock assessments, and therefore a mismatch between the two is reason to revisit respective management regimes (Lundy et al., 1999; Reiss et al., 2009). Here we do not show that subpopulation structures exist within the Scotian Shelf and Southern Grand Banks of Newfoundland Atlantic halibut management unit, but provide reasons to further investigate this possibility.

It is also possible that deviation from the relationship of juvenile:adult abundance (Fig. 3C) may be influenced by ontogenetic shifts in habitat and densitydependent migration. The mechanisms that influence Atlantic halibut movements are not fully understood, but in areas that have reached carrying capacity, it is more likely that animals will emigrate (Fretwell and Lucas 1970; MacCall, 1990). Here, we show a strong positive relationship between habitat suitable for juveniles and commercial landings, and an overlapping distribution of commercial landings and juvenile habitat. This finding is consistent with those from tagging studies that have repeatedly shown that the majority of halibut recaptures are in the area of initial tagging, despite the occasional far-distance movement by an individual (McCracken, 1958; Jensen and Wise, 1961; Neilson et al. ${ }^{5}$; Stobo et al., 1988; Kanwit, 2007; den Heyer et al., 2012; Seitz et al., 2016).

Several next steps can be taken to build on this research and further develop an understanding of Atlantic halibut distribution in the Northwest Atlantic. We limited our model to 5 predictor variables; however additional environmental and community variables, including fishing effort, methods and regulations, prey availability, predation, and interspecific competition, could influence (and potentially improve) the predictive ability of the model. Additionally, by changing existing values of environmental variables (such as temperature or depth), the same model could be used to explore potential changes in suitable-habitat distributions in response to climate change: a valuable resource for planning adaptive measures for a fishery. Overall, our analysis supports the pursuit of future research on potential subpopulation structures and the impact of closed areas on productivity.

Our analysis builds on current ecological knowledge of Atlantic halibut, and can be considered a contribution for future international discussions and assessments of the stock. Our study has shown that suitable habitat can be used as a proxy for juvenile and adult halibut abundance, and that there are areas where population size is below its potential. The Canadian stocks are currently assessed as healthy, and rebuilding is not part of the management objective. However, the occurrence of regions in U.S. waters where abundances remain below expectations indicates that there is room for population growth, which could potentially be achieved through spatial management, more specifically, by the protection of core juvenile habitat. The presence of noteworthy suitable-habitat availability outside the EEZ, off the Grand Banks of Newfoundland also highlights a need for international collaboration. These regions are not regularly surveyed and are subject to international fishing pressures, making them vulnerable to overexploitation. Our maps of suitable habitat can be used by management in the development of user rights in territorial waters and the estab- 
lishment of catch limits or no-take areas. For now, we provide a significant step forward in the characterization of spatial patterns of Atlantic halibut productivity in the Northwest Atlantic, and a contribution to future international discussions and management of the growing fishery for this species.

\section{Acknowledgments}

This research was supported by the Department of Fisheries and Oceans, Canada, and funded by the International Governance Strategy. We thank P. Greyson, M. Koen-Alonso, Z. Wang, and S. Coffen-Smout for extracting and providing data, and K. Frank, C. Stortini, and three anonymous reviewers for insightful and useful comments on earlier versions of the manuscript.

\section{Literature cited}

Anderson, E. D.

1998. The history of fisheries management and scientific advice - the ICNAF/NAFO history from the end of World War II to the present. J. Northwest Atl. Fish. Sci. 23:75-94.

Armsworthy, S. L., M. K. Trzcinski, and S. E. Campana.

2014. Movements, environmental associations, and presumed spawning locations of Atlantic halibut (Hippoglossus hippoglossus) in the northwest Atlantic determined using archival satellite pop-up tags. Mar. Biol. 161:645656. Article

Azarovitz, T. R.

1981. A brief historical review of the Woods Hole Laboratory trawl survey time series. Can. Spec. Publ. Fish. Aquat. Sci. 58:62-67.

Beverton, R. J. H.

1995. Spatial limitation of population size; the concentration hypothesis. Neth. J. Sea Res. 34:1-6. Article

Bigelow, H. B., and W. C. Schroeder.

1953. Atlantic halibut Hippoglossus hippoglossus. In Fishes of the Gulf of Maine, p. 249-258. Fish. Bull. 53.

Boudreau, S. A., N. L. Shackell, S. Carson, and C. E. den Heyer.

2017. Connectivity, persistence, and loss of high abundance areas of a recovering marine fish population in the Northwest Atlantic Ocean. Ecol. Evol. 7:9739-9749. Article

Bowering, W. R.

1986. The distribution, age and growth and sexual maturity of Atlantic halibut (Hippoglossus hippoglossus) in the Newfoundland and Labrador area of the Northwest Atlantic. Can. Tech. Rep. Fish. Aquat. Sci. 1432, 34 p.

Brosse, S., J.-F. Guegan, J.-N. Tourenq, and S. Lek.

1999. The use of artificial neural networks to assess fish abundance and spatial occupancy in the littoral zone of a mesotrophic lake. Ecol. Model. 120:299-311. Article

Butler, S., and S. Coffen-Smout.

2017. Maritimes Region fisheries atlas: catch weight landings mapping (2010-2014). Can. Tech. Rep. Fish. Aquat. Sci. 3199, 57 p.

Cargnelli, L. M., S. J. Griesbach, and W. W. Morse.

1999. Essential fish habitat source document: Atlantic halibut, Hippoglossus hippoglossus, life history and habitat characteristics. NOAA Tech. Memo. NMFS-NE-125, $17 \mathrm{p}$.

Collette, B. B., and G. Klein-MacPhee.

2002. Atlantic halibut/Hippoglossus hippoglossus (Linneaus 1758). In Bigelow and Schroeder's Fishes of the Gulf of Maine, 3rd ed., p. 569-572. Smithsonian Inst. Press, Washington, DC.

Cover, T. M., and J. A. Thomas.

1991. Entropy, relative entropy and mutual information. In Elements of information theory, p. 12-49. John Wiley \& Sons, Inc., New York.

den Heyer, C. E., S. Armsworthy, S. Wilson, G. Wilson, L. Bajona, S. Bond, and M. K. Trzcinski.

2012. Atlantic halibut all-sizes tagging program summary report for 2006 to 2011. Can. Tech. Rep. Fish. Aquat. Sci. 2992, 34 p.

Elith, J., C. H. Graham, R. P. Anderson, M. Dudík, S. Ferrier, A. Guisan, R. Hijmans, F. Huettmann, J. R. Leathwick, A. Lehmann, et al.

2006. Novel methods improve prediction of species' distributions from occurrence data. Ecography 29:129-151. Article

Elith, J., S. J. Phillips, T. Hastie, M. Dudík, Y. E. Chee, and C. J. Yates.

2011. A statistical explanation of MaxEnt for ecologists. Divers. Distrib. 17:43-57. Article

Fitzpatrick, M. C., N. J. Gotelli, and A. M. Ellison.

2013. MaxEnt versus MaxLike: empirical comparisons with ant species distributions. Ecosphere 4(5):1-15. Article

Fogarty, M. J., and S. A. Murawski.

2004. Do marine protected areas really work? Georges Bank experiment offers new insights on age-old questions about closing areas to fishing. Oceanus Magazine $43(2)$.

Fourcade, Y., J. O. Engler, A. G. Besnard, D. Rödder, and J. Secondi.

2013. Confronting expert-based and modelled distributions for species with uncertain conservation status: a case study from the corncrake (Crex crex). Biol. Conserv. 167:161-171. Article

Fretwell, S. D., and H. L. Lucas Jr.

1969. On territorial behaviour and other factors influencing habitat distribution in birds. I. Theoretical development. Acta. Biotheor. 19:16-36. Article

Gaston, K. J., and T. M. Blackburn.

1996. Conservation implications of geographic range size-body size relationships. Conserv. Biol. 10:638-646. Article

Gibson, R. N.

1994. Impact of habitat quality and quantity on the recruitment of juvenile flatfishes. Neth. J. Sea Res. 32:191206. Article

Gillis, D. M., R. M. Peterman, and A. V. Tyler.

1993. Movement dynamics in a fishery: application of the ideal free distribution to spatial allocation of effort. Can. J. Fish. Aquat. Sci. 50:323-333. Article

Godø, O. R., and T. Haug.

1988. Tagging and recapture of Atlantic halibut (Hippoglossus hippoglossus) in Norwegian waters. ICES J. Mar. Sci. 44:169-179. Article

Grasso, G. M.

2008. What appeared limitless plenty: the rise and fall 
of the nineteenth-century Atlantic halibut fishery. Environ. Hist. 13:66-91. Article

Halliday, R. G., and A. T. Pinhorn.

1990. The delimitation of fishing areas in the Northwest Atlantic. J. Northwest Atl. Fish. Sci. 10:1-51.

Halvorsen, R.

2013. A strict maximum likelihood explanation of MaxEnt, and some implications for distribution modelling. Sommerfeltia 36:1-132. Article

Holbrook, S. J., G. E. Forrester, and R. J. Schmitt.

2000. Spatial patterns in abundance of a damselfish reflect availability of suitable habitat. Oecologia 122:109-120. Article

Iles, T. D., and M. Sinclair.

1982. Atlantic herring: stock discreteness and abundance. Science 215:627-633. Article

Jaynes, E. T.

1957. Information theory and statistical mechanics. Phys. Rev. 106:620-630. Article

Jensen, A. C., and J. P. Wise.

1961. Movement of tagged halibut off New EnglandII. Trans. Am. Fish. Soc. 90:489-490. Article

Kanwit, J. K.

2007. Tagging results from the 2000-2004 federal experimental fishery for Atlantic halibut (Hippoglossus hippoglossus) in the eastern Gulf of Maine. J. Northwest Atl. Fish. Sci. 38:37-42. Article

Kearney, M., and W. Porter.

2009. Mechanistic niche modelling: combining physiological and spatial data to predict species' ranges. Ecol. Lett. 12:334-350. Article

Knutsen, H., P. E. Jorde, O. T. Albert, A. R. Hoelzel, and N. C. Stenseth.

2007. Population genetic structure in the North Atlantic Greenland halibut (Reinhardtius hippoglossoides): influenced by oceanic current systems? Can. J. Fish. Aquat. Sci. 64:857-866. Article

Le Bris, A., J. A. D. Fisher, H. M. Murphy, P. S. Galbraith, M. Castonguay, T. Loher, D. Robert, and ed. J. Grabowski.

2017. Migration patterns and putative spawning habitats of Atlantic halibut (Hippoglossus hippoglossus) in the Gulf of St. Lawrence revealed by geolocation of popup satellite archival tags. ICES J. Mar. Sci. fsx098. Article

Lundy, C. J., P. Moran, C. Rico, R. S. Milner, and G. M. Hewitt.

1999. Macrogeographical population differentiation in oceanic environments: a case study of European hake (Merluccius merluccius), a commercially important fish. Mol. Ecol. 8:1889-1898. Article

MacCall, A. D.

1990. geography of marine fish populations, 153 p. Univ.Washington Press, Seattle, WA..

Marshall, C. T., and K. T. Frank.

1995. Density-dependent habitat selection by juvenile haddock (Melanogrammus aeglefinus) on the southwestern Scotian Shelf. Can. J. Fish. Aquat. Sci. 52:1007-1017. Article

McCracken, F.

1958. On the biology and fishery of the Canadian Atlantic halibut, Hippoglossus hippoglossus L. J. Fish. Res. Board Can. 15:1269-1311. Article

Miller, J. M., J. S. Burke, and G. R. Fitzhugh.

1991. Early life history patterns of Atlantic North Ameri- can flatfish: likely (and unlikely) factors controlling recruitment. Neth. J. Sea. Res. 27:261-275. Article

Murphy, H. M., J. A. D. Fisher, A. Le Bris, M. Desgagnés, M. Castonguay, T. Loher, and D. Robert.

2017. Characterization of depth distributions, temperature associations, and seasonal migrations of Atlantic halibut in the Gulf of St. Lawrence using pop-up Satellite archival tags. Mar. Coast. Fish. 9:341-356. Article

Myers, R. A., J. A. Hutchings, and N. J. Barrowman.

1996. Hypotheses for the decline of cod in the North Atlantic. Mar. Ecol. Prog. Ser. 138:293-308. Article

Nielsen, J. K., A. C. Seitz, and ed.: D. Robert.

2017. Interannual site fidelity of Pacific halibut: potential utility of protected areas for management of a migratory demersal fish. ICES J. Mar. Sci. 74:2120-2134. Article

Neilson, J. D., J. F. Kearney, P. Perley, and H. Sampson.

1993. Reproductive biology of Atlantic halibut (Hippoglossus hippoglossus) in Canadian waters. Can. J. Fish. Aquat. Sci. 50:551-563. Article

Pauly, D., R. Hilborn, and T. A. Branch.

2013. Fisheries: does catch reflect abundance? Nature 494:303-306. Article

Phillips, S. J., and M. Dudík.

2008. Modeling of species distributions with Maxent: new extensions and a comprehensive evaluation. Ecography 31:161-175. Article

Phillips, S. J., R. P. Anderson, and R. E. Schapire.

2006. Maximum entropy modeling of species geographic distributions. Ecol. Model. 190:231-259. Article

$\mathrm{R}$ Core Team.

2016. R: a language and environment for statistical computing. R Foundation for Statistical Computing, Vienna, Austria. [Available from website, accessed October 2016.]

Rangeley, R. W., and D. L. Kramer.

1998. Density-dependent antipredator tactics and habitat selection in juvenile pollock. Ecology 79:943-952. Article

Reiss, H., G. Hoarau, M. Dickey-Collas, and W. J. Wolff.

2009. Genetic population structure of marine fish: mismatch between biological and fisheries management units. Fish Fish. 10:361-395. Article

Rijnsdorp, A. D., F. A. Van Beek, S. Flatman, R. M. Millner, J. D. Riley, M. Giret, and R. De Clerck.

1992. Recruitment of sole stocks, Solea solea (L.), in the Northeast Atlantic. Neth. J. Sea. Res. 29:173-192. Article

Seitz, A. C., M. D. Evans, M. B. Courtney, and J. K. Kanwit.

2016. Continental shelf residency by adult Atlantic halibut electronic tagged in the Gulf of Maine. J. Northwest Atl. Fish. Sci. 48:33-40. Article

Shackell, N. L., K. T. Frank, and D. W. Brickman.

2005. Range contraction may not always predict core areas: an example from marine fish. Ecol. Appl. 15:1440 1449. Article

Shackell, N. L., K. T. Frank, J. A. Nye, and C. E. den Heyer. 2016. A transboundary dilemma: dichotomous designations of Atlantic halibut status in the Northwest Atlantic. ICES J. Mar. Sci. 73:1798-1805. Article

Sigourney, D. B., M. R. Ross, J. Brodziak, and J. Burnett.

2006. Length at age, sexual maturity and distribution of Atlantic halibut, Hippoglossus hippoglossus L., off the Northeast USA. J. Northwest Atl. Fish. Sci. 36:81-90. Article

Simon, J. E., and P. A. Comeau.

1994. Summer distribution and abundance trends of spe- 
cies caught on the Scotian Shelf from 1970-1992, by research vessel groundfish survey. Can. Tech. Rep. Fish. Aquat. Sci. 1953, 145 p.

Sterner, T.

2007. Unobserved diversity, depletion and irreversibility: the importance of subpopulations for management of cod stocks. Ecol. Econ. 61:566-574. Article

Stobo, W. T., J. D. Neilson, and P. G. Simpson.

1988. Movements of Atlantic halibut (Hippoglossus hippoglossus) in the Canadian North Atlantic. Can. J. Fish. Aquat. Sci. 45:484-491. Article

Sundblad, G., U. Bergström, A. Sandström, and P. Eklöv.

2014. Nursery habitat availability limits adult stock sizes of predatory coastal fish. ICES J. Mar. Sci. 71:672-680. Article

Swain, D. P., and E. J. Wade.

1993. Density-dependent geographic distribution of Atlantic cod (Gadus morhua) in the southern Gulf of St. Lawrence. Can. J. Fish. Aquat. Sci. 50:725-733. Article
Trumble, R. J., J. D. Neilson, W. R. Bowering, and D. A. McCaughran.

1994. Atlantic Halibut (Hippoglossus hippoglossus) and Pacific Halibut (H. stenolepis) and their North American Fisheries. Can. Bull. Fish. Aquat. Sci. 227, 84 p.

Trzcinski, M. K., and W. D. Bowen.

2016. The recovery of Atlantic halibut: a large, longlived, and exploited marine predator. ICES J. Mar. Sci. 73:1104-1114. Article

VanDerWal, J., L. P. Shoo, C. N. Johnson, and S. E. Williams. 2009. Abundance and the environmental niche: environmental suitability estimated from niche models predicts the upper limit of local abundance. Am. Nat. 174:282291. Article

Wilson, M. T., K. L. Mier, and D. W. Cooper.

2016. Assessment of resource selection models to predict occurrence of five juvenile flatfish species (Pleuronectidae) over the continental shelf in the western Gulf of Alaska. J. Sea Res. 111:54-64. Article 